\title{
Gender Discrimination in the Allocation of Migrant Household Resources *
}

\author{
Francisca M. Antman ${ }^{\dagger}$ \\ Department of Economics, University of Colorado Boulder and IZA
}

January 20, 2015

\begin{abstract}
This paper considers the relationship between international migration and gender discrimination through the lens of decision-making power over intrahousehold resource allocation. The endogeneity of migration is addressed with a difference-in-differences style identification strategy and a model with household fixed effects. The results suggest that while a migrant household head is away, a greater share of resources is spent on girls relative to boys and his spouse commands greater decision-making power. Once the head returns home, however, a greater share of resources goes to boys and there is suggestive evidence of greater authority for the head of household.
\end{abstract}

JEL classification: O15, F22, D13, J16.

Keywords: migration, intrahousehold allocation, gender discrimination, education, bargaining power.

*I thank Terra McKinnish, Richard Akresh, Kate Ambler, Nava Ashraf, Tania Barham, Don Fullerton, Nabanita Datta Gupta, Mary Lopez, Ron Laschever, Darren Lubotsky, Shelly Lundberg, David McKenzie, Robert Pollak, and Elizabeth Powers for their feedback. I also thank three anonymous referees of this Journal, along with the editor, Klaus Zimmermann, for their help and guidance in preparing the final manuscript. Feedback from conference participants at the American Economic Association annual meeting, Northeast Universities Development Consortium Conference, Pacific Conference for Development Economics, Population Association of America annual meeting, Western Economic Association International meeting, and seminar participants at the University of Illinois at UrbanaChampaign, University of Massachusetts Boston, and Federal Reserve Bank of Atlanta is also appreciated. Any errors are my own.

${ }^{\dagger}$ Contact: francisca.antman@colorado.edu, Department of Economics, University of Colorado Boulder, 256 UCB, Boulder, CO 80309. Telephone: 303-492-8872. Fax: 303-4928960 . 


\section{Introduction}

It is now widely acknowledged that parental migration can have important consequences for children that are left behind. ${ }^{1}$ In theory, these effects are not unambiguously positive, due in part to the potentially offsetting influences of migrant remittances and parental absence from the home. But while there is now a large empirical literature evaluating the net impact of parental migration on children's outcomes (Hanson and Woodruff 2003; Yang, 2008; McKenzie and Rapoport 2011; Antman 2011b), much less is known about the mechanisms that underlie these effects. A deeper understanding of this process might also help explain why the overall impact of parental migration on outcomes such as child schooling and work often differs based on child gender (McKenzie and Rapoport 2011; Antman 2012; Cortes 2013). This paper goes beyond estimating the impact of migration on family members left behind to investigate the mechanisms behind these results. This is done by examining how migration affects the gender-specific share of expenditures on education and clothing explicitly, thereby establishing a mechanism whereby paternal migration affects gender discrimination directly. ${ }^{2}$ This investigation is paired with an analysis of self-reported authority over household decisionmaking on these measures to examine whether there are corresponding shifts in decision-making power. The country of focus is Mexico, where men are more likely to migrate and thus be absent from the home, implying an important shift in household structure that would suggest a possible increase in the influence of women left behind. Does migration of the head of household

\footnotetext{
${ }^{1}$ See Antman (2013) for a review of the literature on this topic.

${ }^{2}$ In the absence of data on expenditures by gender of children, an alternative approach might infer discrimination in child expenditures by linking expenditures on adult goods with household gender composition, as in Deaton (1989).
} 
coincide with a shift in expenditures toward girls? Is there a commensurate increase in women's decision-making power?

Linking the impact of migration with changes in the gendered pattern of expenditures and decision-making power also connects this paper with the literature on the allocation of resources within families and households. Studies in this area have largely focused on shifting the balance of bargaining power between men and women by increasing the resources one spouse brings to the household, for instance through targeted cash transfers and government programs (Attanasio and Lechene 2002; Bobonis 2009; Duflo 2003) or labor supply (Antman 2014). This research lies at the heart of the literature on the economics of the family and is most closely associated with testing the unitary or common preference model of the household, the proposition that household decisions can be treated as though they were made by a single decision-maker (Lundberg and Pollak 1996; Thomas 1990). Several studies have found that increasing a woman's bargaining power results in an improvement for girls' health outcomes and not boys (Duflo 2003; Thomas 1994), suggesting that the status quo bargaining process may discriminate against girls and thus contribute to gender gaps in health outcomes. In contrast, this paper suggests an additional way in which women can increase their authority without necessarily changing their resources, but which has for the most part been overlooked: spousal control over the allocation of resources. ${ }^{3}$ Antman (2012) presents evidence in line with this story by showing that a father's migration to the

\footnotetext{
${ }^{3}$ Chen $(2006,2012,2013)$ provides notable exceptions by suggesting that one spouse's migration can lead to imperfect monitoring of time allocations in sending households and thus proposes a mechanism to identify non-cooperative behavior among spouses in China. Unfortunately, the time allocation data for children available in the Mexican data used here does not allow for similar analysis.
} 
U.S. results in statistically significant increases in educational attainment for his daughters, but not his sons. This is consistent with broader evidence that the gender gap in educational attainment has been falling in Mexico (OECD 2014), leading one to question the extent to which the surge in Mexican emigration over the past three decades (Hanson and McIntosh 2010) may have resulted in shifting expenditure patterns toward the education of girls in particular. ${ }^{4}$ Migration and the family separation that it entails can thus provide a window into household decision-making and suggest how women might choose to spend household resources differently were they the sole decision-makers.

To explore these questions, I use data from the Mexican Family Life Survey (MXFLS), a two-wave panel survey which began interviewing respondents in 2002 and again in 2005. Quite significantly, the MXFLS asks questions about permanent and temporary migration and follows Mexican migrants into the United States with a surprisingly high re-contact rate around 90 percent (Rubalcava and Teruel 2007). Importantly, the MXFLS also collects detailed information on household spending, including expenditure data on education and children's clothing by gender. Couples are also individually asked to identify who is responsible for making decisions regarding these expenses.

Estimation is not entirely straightforward, however, because migrants selfselect and thus parental migration may be correlated with the same factors that determine intrahousehold allocations. As in Antman (2011a), I first adopt an

\footnotetext{
${ }^{4}$ Mexican women overall have slightly lower educational attainment than Mexican men (8.6 versus 9.1 years on average), but education levels are roughly similar for 25-34 year-olds (9.4 years for women versus 9.5 for men) (OECD 2014). Note that averages across OECD countries reveal that younger cohorts of women actually display slightly higher levels of educational attainment than men (OECD 2014), suggesting that Mexican women may still make further progress relative to men.
} 
identification strategy inspired by difference-in-differences, where I attempt to net out migrant selection by looking at the set of household heads that have had recent U.S. migration experience and compare those who have already returned to Mexico with those that are still in the U.S. Evidence from this empirical strategy suggests that the share of resources devoted to boys drops when the head of household is in the U.S. However, some may be concerned that return migration to Mexico is endogenous as well, thus contaminating these estimates with an additional selection problem. ${ }^{5}$ For instance, a family that values boys above girls and spends more on boys may also be more likely to send migrants on recurrent trips to the U.S. To address these concerns, I use a household fixed effects strategy that allows me to net out any time-invariant sources of endogeneity that may have resulted in a non-causal correlation between parental migration and children's outcomes.

As with all longitudinal identification strategies, some may be concerned that time-varying sources of endogeneity affect both migration and the allocation of resources within the household. To address this, I first provide suggestive evidence showing no statistically significant differences in the probability a household hits a time-varying observable economic shock based on whether the head has had any recent migration experience. However, some may still be concerned that households hit an unobservable shock between survey waves that induces the father to migrate and also forces children out of school. If boys are more likely to drop out first and enter the work force, as opposed to their sisters dropping out and working in the labor force or at home, this would result in a bias toward the finding that educational expenditures are

\footnotetext{
${ }^{5}$ Such concerns would be consistent with evidence from Campos-Vazquez and Lara (2012) showing that return migrants are negatively selected relative to non-migrants in Mexico over this period of time.
} 
shifted toward girls while fathers are away. Nevertheless, this type of explanation cannot account for the finding that children's clothing expenditures, which explicitly exclude school uniforms, are also shifted toward daughters while fathers are away. In any case, the question remains why boys in particular would receive a lower fraction of resources while their fathers are away versus when they are present. Thus, the use of separate outcome variables related to clothing and educational expenditures casts doubt on competing explanations.

To investigate the mechanism behind these results, I examine data on who is reportedly responsible for making decisions regarding children's education and clothing and link it with data on the migration experience of the head of household. Suggestive evidence from this analysis indicates that while a head is migrating, he is less likely to be responsible for these decisions and his spouse is more likely to be involved in making these choices. Interestingly, some evidence suggests this pattern is reversed when a head has had recent migration experience but is not currently away, i.e. he is more likely to be involved in decisions and his spouse is less likely to be. Together, this evidence is consistent with a story in which the head's decision-making power wanes while he is away, resulting in a shift in resources toward girls, but then resurges upon his return, inducing a relative increase in resources for boys over girls.

The paper proceeds as follows: Section 2 discusses the cross-sectional and longitudinal empirical strategies; Section 3 describes the MXFLS data used in the analysis and reviews summary statistics that preview the results; Section 4 presents the results on the relationship between international migration, household expenditures, and decision-making power; Section 5 interprets the results and Section 6 concludes. 


\section{Empirical strategy}

The ideal experiment to study the effects of parental migration on gender discrimination within the household would randomly select some fraction of Mexican household heads for migration to the U.S., while the remaining household heads stayed at home. ${ }^{6}$ In such an experiment, we could then simply take the difference between the fraction of resources spent on boys for those households with heads in the U.S. and those not in the U.S. as a measure of the effect of migration on the allocation of resources by gender. Of course, the problem in using this measure as our estimate in the real world is that Mexican migrants self-select, and migration could be correlated with unobserved factors affecting household expenditures.

Nevertheless, this hypothetical experiment provides the motivation for a potential identification strategy. By looking within the sample of families where household heads have all had recent migration experience, we can arguably control for the unobserved factors which may have induced migration and may well be correlated with household expenditures. As in Antman (2011a), the idea is to compare families where the head is still absent in the U.S. with those families in which the migrant head has already returned home. In the simplest model with no control variables, it can be estimated as a crosssectional regression model on the sample of all households with heads who have had recent migration experience, but where some heads are still in the U.S.

\footnotetext{
${ }^{6}$ For a similar migration experiment, see Gibson, McKenzie, and Stillman (2008) who evaluate the effects of the New Zealand migration lottery program for families of Tongan migrants. While the omnibus results from these experiments are extensive, they do not examine gender discrimination within the immediate family.
} 
In this hypothetical scenario the sample would include two groups of households:

(a) Households with heads who are currently in the U.S., and thus by definition have had recent U.S. migration experience.

(b) Households with heads who have had recent U.S. migration experience, but have already returned to Mexico.

The independent variable of interest, CurrUSMigit, is an indicator for whether the household head is still in the U.S. and zero otherwise. We could then estimate

$$
Y_{i t}=\alpha_{0}+\alpha_{1} \text { CurrUSMig } g_{i t}+\epsilon_{i t}
$$

where the dependent variable measures the resources spent on boys as a fraction of total resources spent on boys and girls in a specific expenditure category. In this specification, $\alpha_{1}$ is the coefficient of interest because it tells us the additional effect of currently having a head in the U.S. on the expenditure share, over and above any effects due to selection into migration which would be common to those household heads who have recently migrated to the U.S. but have already returned to Mexico.

Alternatively, we can recover the same estimate, $\alpha_{1}$, in a slightly more complex model where we also include the sample of households who have not recently been to the U.S.

Here, the sample includes three groups of households:

(a) Households with heads who are currently in the U.S., and thus by definition have had recent U.S. migration experience.

(b) Households with heads who have had recent U.S. migration experience, but have already returned to Mexico. 
(c) Households with heads who have not recently been to the U.S.

In this specification, it is useful to combine groups (a) and (b) into one group defined by the indicator USMigExper ${ }_{i t}$, which equals one for all households with heads who have recently been to the U.S., regardless of whether they are currently in the U.S. or have already returned to Mexico. We can then estimate

$$
Y_{i t}=\beta_{0}+\beta_{1} \text { USMigExper }{ }_{i t}+\beta_{2} \text { CurrUSMig }_{i t}+\varsigma_{i t} .
$$

Thus, just as in equation (1), we can recover the coefficient of interest, that is $\alpha_{1}=\beta_{2}{ }^{7} \quad$ An advantage of estimating equation (2) as opposed to equation (1) is that it also allows for a comparison of groups (a) and (b) with group (c), households that have not recently experienced migration. More explicitly, $\beta_{1}+\beta_{2}$ gives an estimate of the additional effect of having a head currently in the U.S. relative to having a head that did not migrate. $\beta_{1}$ gives an estimate of the effect of having a head who recently returned from a migration trip relative to having a head that did not migrate since it is only for group (b) that USMigExper $i t=1$ and CurrUSMigit $=0$. While the latter two estimates are potentially biased as they do not control for selection into migration, they do provide a baseline of the OLS estimate which we may later compare with the fixed effects results below. Thus, this type of differencein-differences strategy allows for a direct comparison of outcomes between three groups whose household bargaining structure may have been altered by migration: those who have recently returned from a migration trip, those who are still away, and those with no recent migration experience.

\footnotetext{
${ }^{7}$ Note that with this model, the means of the dependent variable for groups (a), (b), and (c), respectively, are: $\overline{Y_{a}}=\beta_{0}+\beta_{1}+\beta_{2}, \overline{Y_{b}}=\beta_{0}+\beta_{1}, \overline{Y_{c}}=\beta_{0}$.
} 
Including additional controls is straightforward and will form the first regression to be estimated:

$$
Y_{i t}=\beta_{0}+\beta_{1} \text { USMigExper }_{i t}+\beta_{2} \text { CurrUSMig }_{i t}+X_{i t} \delta+\epsilon_{i t} .
$$

The vector of covariates $X_{i t}$, includes the number of household members falling into the following gender and age-specific categories: females 0-5 yearsold, females 6-12 years-old, females 13-17 years-old, females 18-64, and females that are at least 65 years-old. The analogous categories for males are also included, along with dummy variables indicating whether the household is in an urban area, and dummies indicating the survey year and month. Since this cross-sectional regression is implemented on a panel data set, I have included the time subscript over the two waves of the survey $(t=1,2)$ and cluster standard errors at the household level.

The spirit of the identification strategy presented above acknowledges that households may differ due to the endogeneity of out-migration, but comparing households who have all had recent migration experience reduces this problem. An additional challenge is presented by the possibility that return migration to Mexico may also be endogenous. Thus, households with migrant heads who have returned to Mexico by the time of the survey may be different in unobservable ways from households with heads still in the U.S., and it is these differences that may explain differences across households in the gendered allocation of resources. To address this concern, I exploit the panel nature of the MXFLS and run the above regression with household fixed effects:

$$
Y_{i t}=\theta_{1} U S M i g \text { Exper }_{i t}+\theta_{2} \text { CurrUSMig }_{i t}+X_{i t} \phi+\eta_{i}+\varepsilon_{i t},
$$

where $\eta_{i}$ is a household-specific error term constant across both waves of the survey. Thus, controlling for time-invariant factors at the household 
level allows us to net out factors which affect both out- and return migration and which may be correlated with household outcomes. Although the variation identifying the coefficients of interest in equation (4) comes from changes within households over time as opposed to across households, the interpretation of the coefficients of interest remains the same, with the important caveat that we can now make a more robust causal connection between migration and household outcomes. Provided that the selection factors we are concerned about are time-invariant, a compelling feature of this research design is that we can recover causal estimates of the total impact of having a migrant currently in the U.S. relative to the head having remained at home $\left(\theta_{1}+\theta_{2}\right)$, as well the impact of the head recently having returned from a migration trip relative to not having migrated $\left(\theta_{1}\right)$.

As mentioned above, household fixed effects will not address time-varying sources of endogeneity and some may be concerned that a time-varying shock determines both the head's migration patterns and the allocation of resources within his household. For instance, one might expect expenditures in education to shift toward girls if a negative shock determined both that a household head migrated and that his sons dropped out of school to enter the labor market. For this reason, I also consider the expenditure shares on children's clothing, an outcome that explicitly excludes school uniforms, and thus would be expected to move in the opposite direction of education expenditures if such a time-varying shock were behind the results. I also present suggestive evidence from summary statistics showing that observable household economic shocks are not statistically more or less likely in migrant households.

Finally, an investigation of how gender discrimination changes with migration of the head of household would not be complete without some evidence of a mechanism. The analysis below focuses on two classes of decision-making 
outcomes in place of $Y_{i t}$ in equations (1) and (2): the degree to which the household head is involved in making decisions regarding education and children's clothing and the extent to which his spouse is involved in making the same decisions. In this way, the impact of migration on household decisionmaking can be tied to the effect of migration on intrahousehold expenditure patterns.

\section{Data}

\subsection{Description}

The data come from the Mexican Family Life Survey (MXFLS), a collaborative project managed by researchers in Mexico and the United States. ${ }^{8}$ The MXFLS was designed to be a nationally representative panel data set of Mexicans that would follow households regardless of their decisions to reside in Mexico or the U.S. As a result, attrition is remarkably low in the sample, with around 90 percent of the baseline households surveyed in 2002 re-interviewed in the follow-up surveys, taking place mostly in 2005 (Rubalcava and Teruel 2007).

The MXFLS asks respondents detailed questions about income, expenditures, labor supply, schooling choices, and both short- and long-term migration histories. Unfortunately, temporary migration spells lasting less than one year are only documented for the two years immediately prior to the survey. For this reason, the measure of recent migration experience used in this paper is

\footnotetext{
${ }^{8}$ The MXFLS is publicly available at http://www.ennvih-mxfls.org/. Arenas, Conroy, and Nobles (2009) provide an overview of the migration data available, noting current projects and further research possibilities using the data.
} 
limited to any migration experience in the U.S. taking place within the last two years, regardless of duration.

In addition to migration histories, for all household members in Mexico at the time of the baseline survey, the follow-up survey indicates whether they are in the U.S. in the second wave. These migrants make up those observations defined as currently in the U.S. Since these migrants would have had to undertake migration in the interim period between waves, they are also defined as having had recent migration experience, but are distinguished by the fact that they have not returned to Mexico. Since the analysis attempts to link the gendered pattern of expenditures with the gender and decision-making power of the spouse left behind, I limit attention to households headed by men. ${ }^{9}$

The main outcome variables of interest relate to the fraction of educational and children's clothing expenditures spent on boys. ${ }^{10}$ With regard to educational expenses, the survey reports the amount of money spent during the current school period on (1) enrollment, fees, and exams, (2) school utensils and uniforms, and (3) transportation, separately for male and female members in the household. ${ }^{11}$ I add (1)-(3) for each gender separately, and then add

\footnotetext{
${ }^{9}$ Antman (2011a) shows that the cross-sectional expenditure share results for all households are similar, reflecting the predominance of male headship in Mexico.

${ }^{10}$ Other outcome variables of interest would certainly be time allocation variables, such as the amount of time boys and girls spend working and/or in school to facilitate analyses along the lines of Chen $(2012,2006)$. Unfortunately, data limitations prevent me from linking children's time allocations with migration episodes of the head of household.

${ }^{11}$ While the survey does not distinguish between educational expenditures on adults and children, given that average educational attainment is still fairly low in Mexico (roughly 9 years of schooling, OECD, 2014), this arguably stems largely from expenditure on children's education. While the survey contains a separate section indicating educational expenditures on each child, I prefer the measure used here because it is collected in the same manner as the data on clothing expenditures by gender.
} 
these sums together to construct total educational expenditures. I then take the ratio of male educational expenditures over total educational expenditures to construct the boys' educational expenditure share. ${ }^{12}$ I follow a similar procedure to construct the boys' clothing expenditure share based on survey data regarding the amount of money spent on children's clothing and shoes, as well as the value of home production for these goods, for boys and girls over the past three months. ${ }^{13}$ Expenditures on school uniforms are explicitly excluded from the clothing measure and included as educational expenses.

As for the household decision-making data, the MXFLS asks couples individually to report who makes decisions regarding household expenses and time allocation for a variety of outcomes ranging from the food that is eaten in the home to the money that is given to parents and relatives. Respondents are asked to specify who in the household is responsible for making the decision regarding each outcome, and this can include the respondent himself, his spouse, children, mother, father, brother, sister, in-laws, and grandparents. For purposes of this study, I focus on the decisions regarding children's clothing and the education of children. I focus on the household head's responses, which for the most part, identify either him, his spouse, their children, or all of them together as the decision-makers in these categories. Using these data, I generate a binary variable equal to one if the household head reports making the decision alone regarding his children's clothing and zero otherwise. I generate an analogous dummy variable indicating the household head alone makes decisions regarding his children's education. For each expenditure category,

\footnotetext{
${ }^{12}$ All expenditure and income data are deflated using the Mexican CPI and are reported in 2002 Mexican pesos. The CPI data are available from the Banco de Mexico.

${ }^{13}$ The survey collects expenditure information specifically on children's clothing as distinct from clothing for adults.
} 
I also generate analogous variables indicating that (a) the household head is involved in the decision along with anyone else, (b) the spouse alone makes the decision, and (c) the spouse is involved in the decision along with anyone else.

These variables serve as measures of the strength of the household head's decision-making power as well as that of his spouse. The main limitation is that these data are only collected if the individual is present at the time of the survey, so in cases where an individual is not present to respond to the decisionmaking questions, I substitute the response of his or her spouse. Note that this means that when the household head is currently on a migration trip, the responses of his spouse will be used in the analysis. While I primarily focus on the responses of the head of household, Appendix Table A1 reports the results using the spouse's responses to the decision-making questions, showing a similar pattern of results.

\subsection{Summary statistics}

Using boys' expenditure shares as the main outcome variable of interest is useful because they are relatively easy to interpret: an increase in the share implies an increase in the fraction of expenditures spent on boys and conversely, a decrease in the share implies an increase in the fraction spent on girls. Of course, they also present some challenges. First, a share will equal zero if nothing is spent on boys, which would be the case if there were no boys in the household on which to spend. To address this concern, the regressions below control for the age composition of all household members. Second, the outcome variables will be undefined whenever the household reports no expenditures on either girls or boys. This is a harder problem to solve because 
households who do not spend in a particular area are not expressing their views on gender discrimination through the observable lens of expenditures. Thus, I leave households with zero expenditures as missing values, and as can be seen in Table 1, many families have missing values for either clothing or educational expenses. $^{14}$

To be more precise, 7395 household-period observations have non-missing values for either clothing or educational expenditure ratios. Of these, 6267 have non-missing observations for educational expenditures, and 4595 have non-missing values for clothing expenditures. Since cutting the sample size to households with non-missing values for both educational and clothing expenditures results in such a substantial reduction in observations, I perform the main analysis below on both samples. I also report results on the 3467 observations with non-missing values for both educational and clothing expenditure ratios.

\section{[INSERT TABLE 1 HERE]}

\footnotetext{
${ }^{14} \mathrm{An}$ alternative to the expenditure share measure would be the difference in expenditures between boys and girls relative to the sum total expenditure on boys and girls. Using this ratio as the dependent variable yields very similar results, with the main difference being that the range of this variable lies in the $[-1,1]$ range with 0 signifying parity between boys and girls. Thus estimates appear larger in magnitude than the ones presented here, where the range of the dependent variable lies in the $[0,1]$ range and 0.5 signifies parity. Note that this alternative dependent variable would also be undefined whenever total expenditures are zero in this category since they share the same denominator. If one replaces missing values of the alternative dependent variable with zeros, thereby assuming that parity exists whenever no expenditures are made in a given category, the same pattern of results is also obtained but with loss of statistical significance in the total educational expenditure ratio regression in particular. Overall, these robustness checks suggests that neither sample selection nor the specific measure used here is driving the results.
} 
Aside from noting sample sizes, Table 1 presents descriptive statistics for the main samples used in the analysis. Panel A shows that household size is around 5 people on average, with close to one male household member and one female household member in school. The head is about 42 years-old on average, and on average has seven years of education. Close to 40 percent of the sample lives in urban areas, with populations of 100,000 or more. Finally, just under 50 percent of household-period observations are observed in the second wave of the survey, attesting to the low attrition rate in the MXFLS.

Panel B shows the mean and median values on outcome variables of interest. In both clothing and educational expenditures, roughly half of expenditures in each category are spent on boys and girls. Total expenditures in education are much more than total expenditures in clothing, with the former being around five times the latter, based on a comparison of means. The likelihood that the head makes unilateral decisions about children's education and clothing is fairly low in both samples, with only around 5 percent of heads reporting they make unilateral decisions on those margins. The likelihood that the spouse alone makes decisions in these areas appears to be higher, with about 10 percent of households reporting that spouses make unilateral decisions on education and close to 30 percent reporting she is responsible for the clothing decision. Roughly 80 percent of observations report that the head is involved in educational decisions and about 50 percent report his involvement in the clothing decisions. The likelihood that the spouse is involved in the decision is again higher with 87 percent of households reporting she is involved in the education decision and 78 percent reporting that she is involved in the clothing decision. This may simply reflect that both categories relate to children, a realm where women may exert greater influence. 


\section{[INSERT TABLE 2 HERE]}

As mentioned above, it is also useful to cut the sample based on migration experience to get a sense for the ways in which migrant selection and endogeneity more broadly might present a challenge to estimating the impact of migration on outcome variables of interest. Table 2 presents the differences in a set of household characteristics as well as a set of time-varying household shocks collected by the survey to get a sense for whether either is likely to play a role in estimation. To the extent that these observable characteristics and shocks represent good proxies for the types of unobservable characteristics and shocks we might worry about, we can also take this comparison as suggestive evidence to indicate the extent to which time-invariant or time-varying endogeneity concerns are likely to contaminate our estimates. As shown in Table 2, heads with recent migration experience are younger, less educated, and less likely to come from an urban environment on average, relative to the population of households headed by men with no recent migration experience. However, time varying shocks, such as the death or hospitalization of a household member, unemployment or failure of a business, as well as succumbing to natural disasters, or suffering total losses of crop or livestock, are not statistically more or less likely among households where the head has recently migrated or is currently in the U.S. This suggests that while time-invariant selection processes and sources of endogeneity may be important factors correlated both with migration and household outcomes of interest, time-varying shocks may not be as critical. Although purely suggestive, this bolsters the argument that the identification strategies here that rely on controlling for time-invariant characteristics of migrants, either through the construction of a more reasonable comparison group or by using household fixed-effects strate- 
gies, are likely to go a long way to addressing endogeneity concerns associated with migration.

\section{[INSERT TABLE 3 HERE]}

Table 3 begins to preview the results by comparing the mean values of the variables of interest distinguished by the migration experience and current migration status of the head of household. Columns (1) and (4) include the largest group of households with heads that have not recently migrated to the U.S. Columns (2) and (5) includes heads who have recently migrated, but have already returned to Mexico, and columns (3) and (6) includes heads who are currently in the U.S., and by definition have had recent migration experience. The table also gives a window into the relatively small number of recent migrants in these small samples. In the sample with non-missing educational expenditure ratios, 84 households have a head who has had recent migration experience and returned, and an additional 41 heads are in the U.S. The sample of migrants is somewhat smaller in the group with non-missing clothing expenditure ratios, with 71 households in which the head has recently returned from a trip to the U.S. and 28 households in which the head is still absent. Due to these relatively small sample sizes, I estimates the main results on samples with non-missing clothing or educational shares as well as the sample with non-missing clothing and educational expenditure shares. ${ }^{15}$

\footnotetext{
${ }^{15}$ These summary statistics highlight one disadvantage of using the MXFLS data set, namely that the share of migrant households in the data set is very low compared with other surveys that oversample migrant-sending areas, such as the Mexican Migration Project. This may present challenges in the empirical analysis, for instance, the power of hypothesis tests in the fixed effects analysis, because the size of the treated sample is relatively small. As noted above, the advantages of using the MXFLS are that it was designed to be representative of the population and does a relatively good job of limiting attrition over time.
} 
Looking across the category of children's clothing, we see an important pattern emerge: households can be thought to start with expenditures divided somewhat equally among male and female children. If a household head is currently in the U.S., however, the expenditure share falls to 0.45 indicating a shift toward girls. Once the head returns, however, expenditures for boys rise again, leading to an expenditure share about 0.60 . While these differences are statistically significant in the cross-section for the children's clothing category, educational expenditure shares appear to be flat for households when heads are away and rise when they return, but are not statistically significant. Interestingly, total expenditures in children's clothing appear very similar across all migration categories, but appear to fall for both migration groups in the educational category. While these differences are not statistically significant and may in part reflect the higher variance in educational expenditures, I further explore the impact of migration on total expenditures in the regression analysis below.

Table 3 also previews the results surrounding the effects of migration on household decision-making. Here we see a statistically significant drop in the probability that the head makes decisions alone in both education and clothing categories while he is on a migration trip. In fact, no respondents claim that the head is solely responsible for these decisions. There is also a statistically significant drop in the likelihood that he is involved in education decisions. ${ }^{16}$

Also in the education category, Table 3 shows that households are more likely to report that spouses make decisions alone regarding children's education and that spouses are more likely to be involved in that decision when

\footnotetext{
${ }^{16}$ For those concerned that this may reflect the fact that spouses are reporting results while the head is away, Appendix Table A1 shows similar estimates from regressions where the spouse is taken to be the primary respondent.
} 
the head is in the U.S. Another interesting result from the table is the drop in the likelihood that the spouse is responsible for making decisions once the head has returned to Mexico and the corresponding increase in the head's reported involvement in decision-making once he has returned from a migration trip. This may be surprising if we expect households to maintain the decisionmaking roles that were altered during the head's absence. ${ }^{17}$ Instead, these statistics raise the possibility that recent migration confers additional bargaining power on men who are only able to exercise it once they return. It might also reflect a desire on the part of recently absent male heads to compensate for the way in which resources were allocated in their absence and thus explain why heads who have recently migrated appear to be more involved in decisions about children than heads who have not recently left home.

Of course, these differences do not control for other demographic factors that may be changing over time, for instance household size and composition, that could surely affect household expenditures on children. For this reason it will be important to control for these variables in the analysis below. At the same time, return migration may itself be endogenous to household expenditures, and for this reason, it will also be useful to examine the results where household fixed effects are included to net out time-invariant factors that may influence out-migration and return migration, as well as household outcomes.

\section{[INSERT TABLE 4 HERE]}

\footnotetext{
${ }^{17}$ On average, trips to the U.S. last 64.86 weeks (s.d. 134.97), i.e. almost 1 and a quarter years, for heads with any recent migration experience. Since the distribution is so wide, the median may be a better measure of duration, but even that is closer to 7 months, suggesting there are not many trips of very short duration.
} 


\section{Results}

\subsection{Expenditures}

Table 4, Panel A presents the set of cross-sectional and fixed-effects regression results from estimating equations (3) and (4) on the sample of households with non-missing educational and clothing expenditure shares. Here, the statistically significant results exhibit the same pattern exhibited in the summary statistics: a head's recent U.S. migration is associated with an increase in the share of expenditures on boys, but if the head migrated and is still away, there is a decrease in boys' expenditure share. As explained in Section 2, in the cross-sectional regression results, we can also interpret the coefficient on current U.S. migration as a causal estimate of the effect of having a household head migrate on the fraction of resources spent on boys. This estimate is statistically significant at the one percent level for the children's clothing category, showing that migration is associated with a decrease in boys' expenditure share, in other words, a shift toward spending on girls while heads are away. When household fixed-effects are added to the model, the results are stronger and we can recover causal estimates of the effect of current migration and recent migration relative to heads remaining in Mexico. Here, the pattern of results remains the same, and is statistically significant for all coefficients of interest. A head's recent migration is associated with an increase in the expenditure shares favoring boys for both education (point estimate 0.11) and clothing $(0.23)$, relative to heads that remained at home. If the head migrated and is still away, however, expenditure shares drop by 16 percentage points (0.11-0.27) in the education category and 18 percentage points $(0.23-0.41)$ in the clothing category, where the latter estimates are statistically significant at 
the one percent level. Given that the baseline expenditure shares are around 0.5, these appear to be sizable effects. This evidence suggests that the allocation of household resources favors girls while fathers are migrating, and reverses itself to favor boys once fathers have returned from the U.S. ${ }^{18}$

For completeness, Table 4, Panel B reports the results on the sample when either the educational expenditure ratio is non-missing or the clothing expenditure ratio is non-missing. Here the overall pattern of results remains the same, although the magnitudes are smaller and in some cases less precise, as with the results on current U.S. migration in the fixed-effects specification. The statistically significant causal estimates from the cross-sectional results show a drop in boys' clothing expenditure share when a head migrates to the U.S. while the statistically significant fixed effects results indicate that having a head recently return from a migration trip raises the male educational expenditure share.

\section{[INSERT TABLES 5 AND 6 HERE]}

Tables 5 and 6 attempt to explain what drives these results. For brevity, I focus on the fixed effects results where both recent migration experience and current migration estimates can be interpreted as causal. Table 5 analyzes expenditure totals by gender and Table 6 examines educational outcomes to see whether there are substantive effects associated with the change in expenditure shares observed above. For children's clothing, a head's recent migration

\footnotetext{
${ }^{18}$ Some may question whether children are co-migrating with household heads at the time of the survey, raising concerns that the estimate of the impact of paternal migration on children's outcomes is really stemming from the effects of sibling's migration on household expenditure patterns and decision-making. Since there is very little incidence of children migrating in the sample overall, estimating the main results on the sample excluding households with current child migrants produces very similar estimates to those presented here.
} 
experience is associated with a statistically significant rise in boys' and girls' clothing expenditure totals, and the magnitude appears to be larger for boys than for girls (point estimates of 102 versus 87). While educational expenditures for both girls and boys fall with any migration experience, they are not statistically significant, in part reflecting the high variance in educational expenditures. ${ }^{19}$ The results in Table 6 point to a drop in the number of females in school (point estimate -0.20) when the household head has had recent migration experience, with no statistically significant change in the analogous regression for males in school. Additionally, Table 6 examines the expenditure shares for components of schooling expenditures: school fees, school supplies, and school transportation. Both the school fees and school supplies regressions show statistically significant changes favoring boys in those areas (point estimates of 0.118 and 0.086 , respectively) when a head has recently migrated to the U.S. These results support the view that households where heads have recently migrated and returned home are more likely to favor boys in schooling and clothing expenditures.

\subsection{Decision-making}

The question remains as to what explains this shift in household resources favoring girls while fathers are migrating and favoring boys once fathers have returned home. One hypothesis is that father absence allows for an increase in women's decision-making power and subsequently, women shift resources toward their daughters. Once fathers return, however, they have increased bargaining power owing to the increase in resources from the money they have

\footnotetext{
${ }^{19}$ Using a log dependent variable specification yields similar results, but reduces the number of observations.
} 
earned abroad. A related possibility is that fathers feel the need to compensate for the reduced share of resources spent on boys during their absence. While data limitations prohibit an investigation into the father's view of household decision-making while he is absent, we can utilize the spouse's responses to complete the picture of decision-making while he is away. As shown in Appendix Table A1, this is broadly consistent with estimates based mainly on the spouse's responses. ${ }^{20}$

\section{[INSERT TABLE 7 HERE]}

Tables 7 and 8 present the results on the effects of migration on decisionmaking authority primarily using the household head's responses to decisionmaking questions. In Table 7, the sample includes observations with either non-missing education or clothing expenditure shares while Table 8 uses the sample with both non-missing education and non-missing clothing expenditure shares. In the cross-sectional approach adopted in Table 7, Panel A, we can again focus on the comparison of current and former migrants embodied in the coefficient on current U.S. migration to obtain an estimate of the impact of migration on household decision-making. These results show a consistent pattern in which household heads have less decision-making power and their spouses have more decision-making power while the heads are migrating in the U.S. The estimates range from a drop in the probability that the household head is involved in children's education decisions of about 36.2 percentage points (relative to a sample average of 81 percent) to an increase of about 38.1 percentage points in the probability that his spouse makes that decision alone while the head is migrating (relative to a sample average of 9.9 percent). Although the baseline probabilities appear to be markedly different,

\footnotetext{
${ }^{20}$ For brevity, results in the Appendix use the smaller sample.
} 
in a world where migrant household heads are not involved in decision-making and spouses are completely in charge in their absence, it makes sense that these coefficients should be so similar in magnitude. The analogous estimates in Panel B with household fixed effects are also very close in magnitude $(-0.346$ and 0.348 respectively), and both sets are statistically significant at the one percent level. The results for children's clothing also shows similarities across panels $\mathrm{A}$ and $\mathrm{B}$, with both showing that a head is less likely to be involved in decision-making while he is in the U.S. (point estimates around -0.29). While there are fewer statistically significant results for the impact of recent migration experience on decision-making in Panel B, column (1) shows an increase of about 8 percentage points in the probability a head makes a decision alone regarding children's education when he has recently returned from a migration trip. The similarities across panels suggest that any time-invariant selection factors, in particular those correlated with endogenous return migration, are not so large that they skew the estimates in a misleading direction.

\section{[INSERT TABLE 8 HERE]}

To ensure that any sample differences are not driving the results, Table 8 present results for the sample with non-missing clothing and educational expenditure shares. As in Table 7, the overall pattern suggested by the crosssectional results in Panel A suggests an increase in decision-making power if the head has had recent migration experience and a decrease in decision-making power if the head is still away, although the possibility of return migrant selection implies that only the latter estimates can be interpreted as causal. For education, these results indicate that current migration is associated with a drop in the probability that the head is involved in the decision of about 54 percentage points, and again the probability that the spouse alone makes 
the decision in this areas rises by a very similar amount. Also as in Table 7, the household fixed effects specification produces similar estimates (-.57 and .61 , respectively) and these estimates are statistically significant at the one percent level. Results on the impact of recent migration experience for heads that have returned home are somewhat weaker, but also suggest an increase in decision-making power for the head and a decrease for his spouse in panel B.

Overall, the pattern of coefficient estimates across Tables 7 and 8 suggests that households with heads that are currently in the U.S. are less likely to claim that the head has decision-making power and more likely to claim that spouses have decision-making power. Though somewhat weaker, there is also evidence to suggest that household heads with recent migration experience who have returned home are more likely to claim decision-making authority for themselves and less likely to attribute decision-making authority to their wives. Thus, these results are consistent with the view that recent migration experience strengthens the head's decision-making power at the same time that current migration restricts it. For spouses, the pattern is reversed, suggesting an increase in decision-making power while the head is away and a waning of that influence once he has returned.

\section{Discussion}

Taken together, the evidence above suggests a gendered impact of U.S. migration on families in Mexico. First and foremost, households with heads that are currently in the U.S. reduce the share of expenditures on boys relative to girls in both clothing and educational expenditures. One might expect to see this pattern in education if boys were dropping out of school due to some 
income shock associated with the head's migration or because the presence of the head is a complementary input in the schooling production function for boys in particular. However, it is hard to explain why this pattern should also be true for clothing expenditures, particularly if boys work outside of the home instead of going to school and clothing expenditures explicitly include the value of home production. Another possibility is that there are some expenditure items that are not observed, which are actually rising for boys, but unobserved to the researcher ${ }^{21}$ so that if all expenditure categories on boys and girls were taken into account, the distribution would remain unchanged. Still, the fact that households with no recent migration experience seem to start out at parity for girls and boys in both education and clothing expenditures suggests that such a story is unlikely. The evidence that households with heads that have returned home shift expenditures back toward boys also suggests that the movements of expenditure patterns are linked with the presence or absence of the head.

Overall, the results on decision-making power offer suggestive evidence that current migration to the U.S. reduces decision-making power of household heads and increases it for their spouses while the opposite is true for households in which the head has recently returned to Mexico. In this case, a household head's return migration to Mexico raises the share of expenditures on boys relative to girls while it appears to coincide with increases in the head's decision-making power and reductions in the decision-making power of his spouse. At the same time, it should be noted that since the analysis here limits attention to migration in the past two years and the fixed effects results look at migration in the relatively short window between survey waves, it may

\footnotetext{
${ }^{21}$ Thanks to David McKenzie for suggesting this possibility.
} 
still be possible for girls to benefit in the long-run from paternal migration. If migrants are able to stay in the U.S. for a long period of time, girls may be able to maximize the benefit from migration and ultimately raise their educational attainment, as in Antman (2012).

While this paper links migration with shifting expenditure patterns and provides suggestive evidence that changes in household decision-making may drive changes in outcomes for the left behind, one could further ask about the mechanism behind the shift in household decision-making power itself. This could be due to the fact that migrant fathers face challenges in monitoring the allocation of resources at home, as discussed in Chen's (2006) model of Chinese migration. If the head's utility from children is also dependent on his proximity to them, as in Weiss and Willis' (1985) model of divorce settlements, the head's migration may also affect his desire to be involved in household matters to begin with. Another explanation for the set of results presented above would point to changes in relative incomes of the head and his spouse during migration episodes. If the head's income falls relative to his spouse while he is migrating and rises only after he returns, these results would suggest that changes in bargaining power are driven by changes in the relative shares of household income, as documented in Anderson and Eswaran (2009) for example. ${ }^{22}$ This would be consistent with a model in which migration is associated with financial hardship in the near-term (Mckenzie and Rapoport, 2007) and thus migrants require financial support from their spouses at the outset. Unfortunately, insufficient data on the income of the head during migration trips preclude teasing out the extent to which the underlying cause

\footnotetext{
${ }^{22}$ Differences in income elasticities across boys' and girls' goods could also help drive changes in expenditures as in Rose (1999), although potentially with a more complicated mechanism to fully explain the results presented here.
} 
of the shift in decision-making power observed here is due to one or all of these phenomena.

\section{Conclusion}

This paper has assessed the relationship between international migration and the gendered distribution of resources through the lens of household decisionmaking power. The summary statistics, cross-sectional, and longitudinal regressions point to a pattern of a greater share of resources for girls while the head is migrating and his spouse yields greater authority in determining the allocation of household resources. After he has returned to Mexico, however, suggestive evidence points to greater decision-making power for the head and a shift in the share of resources allocated to favor boys.

More generally, linking the decision-making data with the results on expenditure ratios suggests that the identity of the household member responsible for decision-making may play an important role in the underlying mechanism explaining the impact of migration on family members left behind. However, it also poses more questions about why allocations should differ based on the identity of the decision-maker. One possibility is that gender-based preferences are influencing decisions over children-the simplest story being that men prefer boys and women prefer girls. Another possibility is that investments in girls versus boys and their associated returns are viewed differently by the head and his spouse. Further research should attempt to disentangle these competing hypotheses and determine whether policies may be structured to ensure equitable allocations for girls and boys regardless of who is in charge of the allocation of resources.

Ironically, the potential policy implications may run counter to those from 
other studies such as Ashraf et al. (forthcoming) who show that allowing migrants more control over resource allocation boosts savings for Salvadorean migrants. Instead, the results presented here suggest that implementing a program that increases migrant control over resources at home may have mixed consequences for girls if they effectively benefit from a migrant's lack of control while he is away. If so, it would not be enough to suggest that there are winners and losers from migration, but more accurate to say that the distributions of gains and losses may even be unbalanced within the sending household itself. 


\section{References}

Anderson, S, M Eswaran (2009) What determines female autonomy? Evidence from Bangladesh. J Dev Econ 90(2): 179-191

Antman, FM (2014) Spousal employment and intra-household bargaining power. Appl Econ Lett 21(8): 560-63

Antman, FM (2013) The impact of migration on family left behind. In: AF Constant and KF Zimmermann (eds.), International handbook on the economics of migration. Edward Elgar, Northampton, MA

Antman, FM (2012) Gender, educational attainment and the impact of parental migration on children left behind. J Popul Econ 25(4): 1187-1214

Antman, FM (2011a) International migration and gender discrimination among children left behind. Amer Econ Review 101(3): 645-49

Antman, FM (2011b) The intergenerational effects of paternal migration on schooling and work: what can we learn from children's time allocations? J Dev Econ 96(2): 200-208

Arenas, E, H Conroy, and J Nobles (2009) Recent trends in internal and international Mexican migration: evidence from the Mexican Family Life Survey. California Center for Population Research On-Line Working Paper, CCPR-2008-034

Ashraf, N, D Aycinena, C Martinez and D Yang (forthcoming) Savings in transnational households: a field experiment among migrants from El Sal- 
vador. Rev Econ Stat

Attanasio, O, V Lechene (2002) Tests of income pooling in household decisions. Rev Econ Dyn 5: 720-748

Bobonis, G (2009) Is the allocation of resources within the household efficient? New evidence from a randomized experiment, J Political Econ, 117 (3): 453503

Campos-Vazquez, RM, J Lara (2012) Self-selection patterns among return migrants: Mexico 1990-2010. IZA J Migration 1:8

Chen, JJ (2013) Identifying non-cooperative behavior among spouses: child outcomes in migrant-sending households. J Dev Econ 100(1): 1-18

Chen, JJ (2012) Dads, disease, and death: determinants of daughter discrimination. J Pop Econ 25 (1): 119-149

Chen, JJ (2006) Migration and imperfect monitoring: implications for intrahousehold allocation. Amer Econ Review, 96(2): 227-231

Cortes, P (2013) The feminization of international migration and its effects on the children left behind: evidence from the Philippines. World Dev, 65: $62-78$

Deaton, A (1989) Looking for boy-girl discrimination in household expenditure data. World Bank Econ Rev 3(1): 1-15

Duflo, E (2003) Grandmothers and granddaughters: old-age pensions and intrahousehold allocation in South Africa World Bank Econ Rev 17(1): 1-25 
Gibson, J, D McKenzie, S Stillman (2011) The impacts of international migration on remaining household members: omnibus results from a migration lottery program. Rev Econ Stat 93(4): 1297-1318

Hanson, GH, C McIntosh (2010) The great Mexican emigration. Rev Econ Stat 92(4): 798-810

Hanson, GH, C Woodruff (2003) Emigration and educational attainment in Mexico." Unpublished Manuscript. University of California, San Diego

Hildebrandt, N, D McKenzie (2005) The effects of migration on child health in Mexico. Economia 6(1): 257-89

Lundberg, S, RA Pollak (2007) The American family and family economics J Econ Perspect 21(2): 3-26

Lundberg, S, RA Pollak (1996) Bargaining and distribution in marriage J Econ Perspect 10(4): 139-158

McKenzie, D, H Rapoport (2011) Can migration reduce educational attainment? Evidence from Mexico.” J Popul Econ 24(4): 1331-58

Mckenzie, D, H Rapoport (2007) Network effects and the dynamics of migration and inequality: theory and evidence from Mexico." J Dev Econ 84(1): $1-24$

Organization for Economic Cooperation and Economic Development (2014) CO3.1: educational attainment by gender and average years spent in formal education. 
http://www.oecd.org/els/family/CO_3_1_Educational_attainment_by_gender_Sep2014.pdf

Rubalcava, L, G Teruel (2007) The Mexican family life survey first wave. Working paper. http://www.ennvih-mxfls.org/

Rubalcava, L, G Teruel (2007) User's guide: Mexican family life survey 2005. Working paper. http://www.ennvih-mxfls.org/

Thomas, D (1990) Intra-household resource allocation: an inferential approach.” J Hum Resour, 25(4): 635-664

Thomas, D (1994) Like father, like son; like mother, like daughter: parental resources and child height. J Hum Resour, 29(4): 950-988

Weiss, Y, RJ Willis (1985) Children as collective goods and divorce settlements. J Labor Econ, 3(3): 268-92

Yang, D (2008) International migration, remittances and household investment: evidence from Philippine migrants' exchange rate shocks." Econ J, 118: $591-630$ 
Table 1: Descriptive Statistics

Panel A: Full Sample based on non-missing expenditures in either education or clothing

\begin{tabular}{lcc}
\hline & Mean & SD \\
Household Size & 5.15 & 1.81 \\
Head's years of education & 7.15 & 4.17 \\
Head's age & 42.12 & 11.72 \\
Number of Male Household Members in School & 0.91 & 0.90 \\
Number of Female Household Members in School & 0.93 & 0.91 \\
Urban & 0.38 & 0.49 \\
Second Wave of Survey & 0.48 & 0.50 \\
& & \\
Observations (non-missing clothing or educational exp.) & 7395 & \\
\hline
\end{tabular}

Panel B: Split Samples based on non-missing expenditures in this category

\begin{tabular}{lcccc}
\hline \hline & \multicolumn{2}{c}{ Education } & & \multicolumn{2}{c}{ Children's Clothing } \\
\cline { 2 - 5 } Male Expenditure /Total expenditure in this category & Mean & SD & Mean & SD \\
Total expenditure in this category & 0.52 & 0.40 & 0.51 & 0.41 \\
Head alone makes decision about children in this category & 0.05 & 0.21 & 0.04 & 0.19 \\
Head involved in decision about children in this category & 0.81 & 0.39 & 0.49 & 0.50 \\
Spouse alone makes decision about children in this category & 0.10 & 0.30 & 0.29 & 0.45 \\
Spouse involved in decision about children in this category & 0.87 & 0.34 & 0.78 & 0.41 \\
Observations & & & & \\
\hline
\end{tabular}




(1) (2)

No Recent Recent

Experience; Experience,

Not currently Including

in US currently in US

$\underline{\text { Household Characteristics }}$

Head's Education

$\begin{array}{cc}7.16 & 6.59 * \\ 4.18 & 3.79 \\ 42.20 & 38.12^{* * *} \\ 11.75 & 9.50 \\ 0.39 & 0.23^{* * *} \\ 0.49 & 0.42\end{array}$

Household Shocks Occurring in the Past 5 Years

Death of a household member

$0.06 \quad 0.07$

$0.24 \quad 0.26$

Hospitalization of a household member due to accident or illness

$0.13 \quad 0.09$

$0.33 \quad 0.29$

Unemployment/business failure of a household member

$0.08 \quad 0.09$

$0.27 \quad 0.29$

$0.01 \quad 0.01$

House or business loss due to natural disaster

$0.11 \quad 0.08$

Total loss of crop

$0.04 \quad 0.03$

$0.20 \quad 0.18$

Loss or death of production animals

$0.02 \quad 0.03$

$0.12 \quad 0.16$

Observations (non-missing clothing or educational exp.)

7243

152

Standard deviation below mean

In column (2): ***(1)-(2) $\mathrm{p}<0.01 ; * *(1)-(2) \mathrm{p}<0.05 ; *(1)-(2) \mathrm{p}<0.10$ 
Table 3: Expenditures \& Decision-Making by Head's US Migration Experience

\section{Sample (based on non-missing}

(1)

No Recent

Experience

(2)

(3)

Experience

Experience

Not Currently Not Currently Currently in

in US

in US

US

Male Expenditure /Total expenditure in category

Total expenditure in category

Head alone makes decision about children in this category

Head involved in decision about children in this category

Spouse alone makes decision about children in this category

Spouse involved in decision about children in this category

Number of observations

$\begin{array}{ccc}0.52 & 0.56 & 0.52 \\ 0.40 & 0.41 & 0.38 \\ 3002 & 2056 & 1213 \\ 20117 & 4740 & 1394\end{array}$

$\begin{array}{llc}0.05 & 0.08 & 0 * * * \\ 0.21 & 0.28 & 0.00\end{array}$

0.81

0.39

$0.89 * *$

0.31

$0.59 * * *$

0.50

0.10

$0.05^{* *}$

$0.41 * * *$

0.30

0.21

0.50

\subsection{7}

0.34

6142
0.87

0.34

84

$1 * * *$
0.00
41

expenditures in this category)

(4)

Children's Clothing

No Recent Recent Recent

(5)

(6)

Experience Experience Experience Not

Not Currently Currently Currently in in US in US US

$\begin{array}{ccc}0.51 & 0.60 * & 0.45^{*} \\ 0.41 & 0.40 & 0.37 \\ 548 & 536 & 597 \\ 698 & 487 & 607 \\ & & \\ 0.04 & 0.10 * & 0 * * * \\ 0.19 & 0.30 & 0.00\end{array}$

$\begin{array}{lll}0.49 & 0.49 & 0.32\end{array}$

$\begin{array}{lll}0.50 & 0.50 & 0.48\end{array}$

Standard deviation below mean

In column (2): ***(1)-(2) $\mathrm{p}<0.01 ; * *(1)-(2) \mathrm{p}<0.05 ; *$ (1)-(2) $\mathrm{p}<0.10$

In column (3): *** (2)-(3) $\mathrm{p}<0.01$; ** (2)-(3) $\mathrm{p}<0.05$; * (2)-(3) $\mathrm{p}<0.10$

In column (5): ***(4)-(5) $\mathrm{p}<0.01$; **(4)-(5) $\mathrm{p}<0.05$; * (4)-(5) $\mathrm{p}<0.10$

In column (6): *** (5)-(6) $\mathrm{p}<0.01$; ** (5)-(6) $\mathrm{p}<0.05$; * (5)-(6) $\mathrm{p}<0.10$

0.29

$0.39 * \quad 0.46$

$\begin{array}{lll}0.45 & 0.49 & 0.51\end{array}$

$\begin{array}{ccc}0.78 & 0.80 & 0.82 \\ 0.41 & 0.40 & 0.39 \\ 4496 & 71 & 28\end{array}$


Table 4: Migration and Gender Expenditure Shares

Panel A: Non-missing in both expenditure share categories

\begin{tabular}{lcccc}
\hline \hline & $(1)$ & $(2)$ & $(3)$ & $(4)$ \\
& $\begin{array}{c}\text { Male Edu } \\
\text { Exp Share }\end{array}$ & $\begin{array}{c}\text { Male Edu } \\
\text { Exp Share }\end{array}$ & $\begin{array}{c}\text { Boys' Clothing } \\
\text { Exp Share }\end{array}$ & $\begin{array}{c}\text { Boys' } \\
\text { Clothing Exp } \\
\text { Share }\end{array}$ \\
Head: Any Recent US & 0.048 & 0.113 & 0.124 & 0.225 \\
Migration Experience & $(0.045)$ & $(0.066)^{*}$ & $(0.035)^{* * *}$ & $(0.097)^{* *}$ \\
Head: Currently in US & 0.006 & -0.268 & -0.188 & -0.405 \\
Mean of Dep. Var. & $(0.076)$ & $(0.145)^{*}$ & $(0.069)^{* * *}$ & $(0.139)^{* * *}$ \\
Household Fixed Effects & 0.521 & 0.521 & 0.512 & 0.512 \\
Number of Observations & NO & YES & NO & YES \\
\hline & 3,467 & 3,467 & 3,467 & 3,467 \\
Panel B: Non-missing in either expenditure ratio category & & \\
\hline \hline & $(1)$ & $(2)$ & $(3)$ & $(4)$ \\
& Male Edu & Male Edu & Boys' Clothing & Boys' \\
& Exp Share & Exp Share & Exp Share & Share \\
Head: Any Recent US & 0.027 & 0.092 & 0.080 & 0.033 \\
Migration Experience & $(0.038)$ & $(0.046)^{* *}$ & $(0.034)^{* *}$ & $(0.070)$ \\
Head: Currently in US & 0.050 & -0.069 & -0.107 & -0.167 \\
Mean of Dep. Var. & $(0.057)$ & $(0.096)$ & $(0.064)^{* *}$ & $(0.122)$ \\
Household Fixed Effects & 0.521 & 0.521 & 0.513 & 0.513 \\
Number of Observations & NO & YES & NO & YES \\
\hline Robust standard & 6,267 & 6,267 & 4,595 & 4,595 \\
\hline
\end{tabular}

Robust standard errors clustered at the household level reported in parentheses below point estimates

Clothing expenditures include value of home production, if any

Other covariates: Number of household members in gender and age-specific groups,

dummies for survey year, dummies for survey month, urban dummy

$* p<0.1 ; * * p<0.05 ; * * * p<0.01$ 
Table 5: Migration and Expenditure Totals by Gender

Household Fixed Effects Regressions

\begin{tabular}{lcccccc}
\hline \hline & $(1)$ & $(2)$ & $(3)$ & $(4)$ & $(5)$ & $(6)$ \\
& $\begin{array}{c}\text { Kids' Clothing } \\
\text { Exp Total }\end{array}$ & $\begin{array}{c}\text { Boys' } \\
\text { Clothing } \\
\text { Total }\end{array}$ & $\begin{array}{c}\text { Girls' Clothing } \\
\text { Total }\end{array}$ & $\begin{array}{c}\text { Education } \\
\text { Exp Total }\end{array}$ & Male Edu Exp Female Edu Exp \\
Head: Any Recent US & 188.679 & 101.680 & 86.999 & -628.208 & -423.861 & -204.347 \\
Migration Experience & $(70.776)^{* * *}$ & $(45.677)^{* *}$ & $(43.252)^{* *}$ & $(646.171)$ & $(709.039)$ & $(341.283)$ \\
Head: Currently in US & -147.297 & -115.307 & -31.990 & -376.714 & -32.479 & -344.235 \\
Mean of Dep. Var. & $(178.453)$ & $(93.590)$ & $(111.363)$ & $(862.561)$ & $(842.749)$ & $(446.189)$ \\
Number of Observations & 548.216 & 276.287 & 271.929 & 2977.876 & 1479.512 & 1498.364 \\
\hline
\end{tabular}

Robust standard errors clustered at the household level reported in parentheses below point estimates

Clothing expenditures include value of home production, if any

Other covariates: Number of household members in gender and age-specific groups, dummies for survey year, dummies for survey month, urban dummy

$* p<0.1 ; * * p<0.05 ; * * * p<0.01$ 
Table 6: Migration and Gender Discrimination in Education

Household Fixed Effects Regressions

(1)

$(2)$

(4)

(5)

\begin{tabular}{ccccc} 
Males in & Females in & \multicolumn{2}{c}{ Male } & Male School \\
School & School & $\begin{array}{c}\text { Male School } \\
\text { Share }\end{array}$ & $\begin{array}{c}\text { Supplies } \\
\text { Share }\end{array}$ & $\begin{array}{c}\text { Transport } \\
\text { Share }\end{array}$ \\
0.012 & -0.203 & 0.118 & 0.086 & -0.006 \\
$(0.076)$ & $(0.078)^{* * *}$ & $(0.050)^{* *}$ & $(0.052)^{*}$ & $(0.115)$ \\
0.159 & -0.178 & -0.066 & -0.140 & 0.122 \\
$(0.150)$ & $(0.132)$ & $(0.119)$ & $(0.101)$ & $(0.256)$ \\
1.009 & 1.034 & 0.526 & 0.520 & 0.493 \\
6,267 & 6,267 & 5,648 & 5,974 & 2,139 \\
\hline
\end{tabular}

Head: Any Recent US

Migration Experience

Head: Currently in US

Mean of Dep. Var.

6,267

Number of Observations

Robust standard errors clustered at the household level reported in parentheses below point estimates

Clothing expenditures include value of home production, if any

Other covariates: Number of household members in gender and age-specific groups, dummies for survey year, dummies for survey month, urban dummy

$* p<0.1 ; * * p<0.05 ; * * * p<0.01$ 
Table 7: Migration and Household Decision-Making ${ }^{1}$

Panel A: Cross-sectional Regressions

\begin{tabular}{|c|c|c|c|c|c|c|c|c|}
\hline & \multicolumn{4}{|c|}{ Children's Education Decision } & \multicolumn{4}{|c|}{ Children's Clothing Decision } \\
\hline & (1) & (2) & (3) & (4) & (5) & (6) & (7) & (8) \\
\hline & $\begin{array}{c}\text { Head Alone } \\
\text { Makes } \\
\text { Decision }\end{array}$ & $\begin{array}{c}\text { Head } \\
\text { Involved in } \\
\text { Decision }\end{array}$ & $\begin{array}{c}\text { Spouse Alone } \\
\text { Makes } \\
\text { Decision }\end{array}$ & $\begin{array}{c}\text { Spouse } \\
\text { Involved in } \\
\text { Decision }\end{array}$ & $\begin{array}{c}\text { Head Alone } \\
\text { Makes } \\
\text { Decision }\end{array}$ & $\begin{array}{c}\text { Head } \\
\text { Involved in } \\
\text { Decision }\end{array}$ & $\begin{array}{c}\text { Spouse } \\
\text { Alone } \\
\text { Makes } \\
\text { Decision }\end{array}$ & $\begin{array}{c}\text { Spouse } \\
\text { Involved in } \\
\text { Decision }\end{array}$ \\
\hline Head: Any Recent US & 0.034 & 0.048 & -0.055 & -0.033 & 0.059 & -0.015 & 0.096 & -0.001 \\
\hline Migration Experience & $(0.030)$ & $(0.032)$ & $(0.023)^{* *}$ & $(0.036)$ & $(0.036)^{*}$ & $(0.060)$ & $(0.059)$ & $(0.048)$ \\
\hline \multirow{2}{*}{ Head: Currently in US } & -0.080 & -0.362 & 0.381 & 0.092 & -0.105 & -0.289 & 0.081 & -0.087 \\
\hline & $(0.031)^{* * *}$ & $(0.085)^{* * *}$ & $(0.080)^{* * *}$ & $(0.040)^{* *}$ & $(0.037)^{* * *}$ & $(0.107)^{* * *}$ & $(0.111)$ & $(0.084)$ \\
\hline Mean of Dep. Variable & 0.048 & 0.811 & 0.099 & 0.867 & 0.039 & 0.492 & 0.291 & 0.782 \\
\hline Observations & 6,267 & 6,267 & 6,267 & 6,267 & 4,595 & 4,595 & 4,595 & 4,595 \\
\hline
\end{tabular}

Panel B: Household Fixed Effects Regressions

\begin{tabular}{|c|c|c|c|c|c|c|c|c|}
\hline & \multicolumn{4}{|c|}{ Children's Education Decision } & \multicolumn{4}{|c|}{ Children's Clothing Decision } \\
\hline & (1) & $(2)$ & (3) & (4) & (5) & (6) & (7) & (8) \\
\hline & $\begin{array}{c}\text { Head Alone } \\
\text { Makes } \\
\text { Decision }\end{array}$ & $\begin{array}{c}\text { Head } \\
\text { Involved in } \\
\text { Decision }\end{array}$ & $\begin{array}{c}\text { Spouse Alone } \\
\text { Makes } \\
\text { Decision }\end{array}$ & $\begin{array}{c}\text { Spouse } \\
\text { Involved in } \\
\text { Decision }\end{array}$ & $\begin{array}{l}\text { Head Alone } \\
\text { Makes } \\
\text { Decision }\end{array}$ & $\begin{array}{c}\text { Head } \\
\text { Involved in } \\
\text { Decision }\end{array}$ & $\begin{array}{l}\text { Spouse } \\
\text { Alone } \\
\text { Makes } \\
\text { Decision }\end{array}$ & $\begin{array}{c}\text { Spouse } \\
\text { Involved in } \\
\text { Decision }\end{array}$ \\
\hline Head: Any Recent US & 0.081 & 0.088 & -0.092 & -0.066 & -0.006 & -0.078 & 0.171 & 0.026 \\
\hline Migration Experience & $(0.047)^{*}$ & $(0.074)$ & $(0.062)$ & $(0.059)$ & $(0.057)$ & $(0.105)$ & $(0.105)$ & $(0.092)$ \\
\hline Hoad. Currently in IS & -0.062 & -0.346 & 0.348 & 0.055 & 0.050 & -0.292 & 0.177 & -0.155 \\
\hline Head: currentiy in us & $(0.050)$ & $(0.128)^{* * *}$ & $(0.118)^{* * *}$ & $(0.065)$ & $(0.058)$ & $(0.172)^{*}$ & $(0.169)$ & $(0.157)$ \\
\hline Mean of Dep. Variable & 0.048 & 0.811 & 0.099 & 0.867 & 0.039 & 0.492 & 0.291 & 0.782 \\
\hline Observations & 6,267 & 6,267 & 6,267 & 6,267 & 4,595 & 4,595 & 4,595 & 4,595 \\
\hline
\end{tabular}

${ }^{1}$ Reported by head, except when missing, in which case responses of spouse are substituted

Robust standard errors clustered at the household level reported in parentheses below point estimates

Clothing expenditures include value of home production, if any

Other covariates: Number of household members in gender and age-specific groups, dummies for survey year, dummies for survey month, urban dummy

${ }^{*} p<0.1 ; * * p<0.05 ; * * * p<0.01$ 
Table 8: Migration and Household Decision-Making ${ }^{1}$ in Smaller Sample

Panel A: Cross-sectional Regressions

\begin{tabular}{|c|c|c|c|c|c|c|c|c|}
\hline & \multicolumn{4}{|c|}{ Children's Education Decision } & \multicolumn{4}{|c|}{ Children's Clothing Decision } \\
\hline & (1) & (2) & (3) & (4) & (5) & (6) & (7) & (8) \\
\hline & $\begin{array}{c}\text { Head Alone } \\
\text { Makes } \\
\text { Decision }\end{array}$ & $\begin{array}{c}\text { Head } \\
\text { Involved in } \\
\text { Decision }\end{array}$ & $\begin{array}{l}\text { Spouse } \\
\text { Alone } \\
\text { Makes } \\
\text { Decision }\end{array}$ & $\begin{array}{c}\text { Spouse } \\
\text { Involved in } \\
\text { Decision }\end{array}$ & $\begin{array}{c}\text { Head } \\
\text { Alone } \\
\text { Makes } \\
\text { Decision }\end{array}$ & $\begin{array}{c}\text { Head } \\
\text { Involved in } \\
\text { Decision }\end{array}$ & $\begin{array}{l}\text { Spouse } \\
\text { Alone } \\
\text { Makes } \\
\text { Decision }\end{array}$ & $\begin{array}{c}\text { Spouse } \\
\text { Involved in } \\
\text { Decision }\end{array}$ \\
\hline Head: Any Recent US & 0.047 & 0.079 & -0.043 & -0.015 & 0.074 & 0.066 & -0.008 & -0.037 \\
\hline Migration Experience & $(0.041)$ & $(0.031)^{* *}$ & $(0.032)$ & $(0.042)$ & $(0.044)^{*}$ & $(0.068)$ & $(0.062)$ & $(0.057)$ \\
\hline \multirow{2}{*}{ Head: Currently in US } & -0.100 & -0.540 & 0.519 & 0.078 & -0.125 & -0.322 & 0.128 & -0.050 \\
\hline & $(0.043)^{* *}$ & $(0.115)^{* * *}$ & $(0.116)^{* * *}$ & $(0.047)$ & $(0.046)^{* * *}$ & $(0.126)^{* *}$ & $(0.125)$ & $(0.103)$ \\
\hline Mean of Dep. Variable & 0.047 & 0.842 & 0.102 & 0.901 & 0.039 & 0.488 & 0.286 & 0.778 \\
\hline Observations & 3,467 & 3,467 & 3,467 & 3,467 & 3,467 & 3,467 & 3,467 & 3,467 \\
\hline
\end{tabular}

Panel B: Household Fixed Effects Regressions

\begin{tabular}{|c|c|c|c|c|c|c|c|c|}
\hline & \multicolumn{4}{|c|}{ Children's Education Decision } & \multicolumn{4}{|c|}{ Children's Clothing Decision } \\
\hline & $(1)$ & $(2)$ & (3) & (4) & $(5)$ & (6) & (7) & (8) \\
\hline & $\begin{array}{c}\text { Head Alone } \\
\text { Makes } \\
\text { Decision }\end{array}$ & $\begin{array}{c}\text { Head } \\
\text { Involved in } \\
\text { Decision }\end{array}$ & $\begin{array}{c}\text { Spouse } \\
\text { Alone } \\
\text { Makes } \\
\text { Decision }\end{array}$ & $\begin{array}{c}\text { Spouse } \\
\text { Involved in } \\
\text { Decision }\end{array}$ & $\begin{array}{l}\text { Head } \\
\text { Alone } \\
\text { Makes } \\
\text { Decision }\end{array}$ & $\begin{array}{c}\text { Head } \\
\text { Involved in } \\
\text { Decision }\end{array}$ & $\begin{array}{l}\text { Spouse } \\
\text { Alone } \\
\text { Makes } \\
\text { Decision }\end{array}$ & $\begin{array}{c}\text { Spouse } \\
\text { Involved in } \\
\text { Decision }\end{array}$ \\
\hline Head: Any Recent US & 0.122 & 0.091 & -0.098 & -0.134 & 0.130 & 0.022 & 0.120 & -0.053 \\
\hline Migration Experience & $(0.076)$ & $(0.065)$ & $(0.063)$ & $(0.077)^{*}$ & $(0.076)^{*}$ & $(0.145)$ & $(0.141)$ & $(0.131)$ \\
\hline \multirow{2}{*}{ Head: Currently in US } & -0.103 & -0.567 & 0.610 & 0.155 & -0.098 & -0.336 & 0.063 & -0.165 \\
\hline & $(0.085)$ & $(0.163)^{* * *}$ & $(0.160)^{* * *}$ & $(0.094)^{*}$ & $(0.078)$ & $(0.223)$ & $(0.205)$ & $(0.183)$ \\
\hline Mean of Dep. Variable & 0.047 & 0.842 & 0.102 & 0.901 & 0.039 & 0.488 & 0.286 & 0.778 \\
\hline Observations & 3,467 & 3,467 & 3,467 & 3,467 & 3,467 & 3,467 & 3,467 & 3,467 \\
\hline
\end{tabular}

${ }^{1}$ Reported by head, except when missing, in which case responses of spouse are substituted

Robust standard errors clustered at the household level reported in parentheses below point estimates

Clothing expenditures include value of home production, if any

Other covariates: Number of household members in gender and age-specific groups, dummies for survey year, dummies for survey month, urban dummy

${ }^{*} p<0.1 ; * * p<0.05 ; * * * p<0.01$ 
Appendix Table A1: Spouse's Household Decision-Making Responses ${ }^{1}$ and Head's Recent Migration in Smaller Sample

Panel A: Cross-sectional Regressions

\begin{tabular}{|c|c|c|c|c|c|c|c|c|}
\hline & \multicolumn{4}{|c|}{ Children's Education Decision } & \multicolumn{4}{|c|}{ Children's Clothing Decision } \\
\hline & (1) & (2) & (3) & (4) & (5) & (6) & (7) & (8) \\
\hline & $\begin{array}{c}\text { Head Alone } \\
\text { Makes } \\
\text { Decision }\end{array}$ & $\begin{array}{c}\text { Head } \\
\text { Involved in } \\
\text { Decision }\end{array}$ & $\begin{array}{l}\text { Spouse } \\
\text { Alone } \\
\text { Makes } \\
\text { Decision }\end{array}$ & $\begin{array}{c}\text { Spouse } \\
\text { Involved in } \\
\text { Decision }\end{array}$ & $\begin{array}{c}\text { Head } \\
\text { Alone } \\
\text { Makes } \\
\text { Decision }\end{array}$ & $\begin{array}{c}\text { Head } \\
\text { Involved in } \\
\text { Decision }\end{array}$ & $\begin{array}{l}\text { Spouse } \\
\text { Alone } \\
\text { Makes } \\
\text { Decision }\end{array}$ & $\begin{array}{c}\text { Spouse } \\
\text { Involved in } \\
\text { Decision }\end{array}$ \\
\hline Head: Any Recent US & -0.017 & 0.017 & 0.002 & 0.032 & -0.013 & 0.037 & -0.066 & -0.035 \\
\hline Migration Experience & $(0.019)$ & $(0.050)$ & $(0.048)$ & $(0.027)$ & $(0.020)$ & $(0.066)$ & $(0.064)$ & $(0.055)$ \\
\hline Iord $C$ in & -0.004 & -0.429 & 0.432 & 0.006 & -0.021 & -0.228 & 0.117 & -0.051 \\
\hline Head: currentiy in us & $(0.021)$ & & $(0.123)^{* * *}$ & $(0.034)$ & $(0.021)$ & $(0.125)^{*}$ & $(0.126)$ & $(0.098)$ \\
\hline Mean of Dep. Variable & 0.034 & 0.807 & 0.132 & 0.909 & 0.028 & 0.424 & 0.320 & 0.771 \\
\hline Observations & 3,467 & 3,467 & 3,467 & 3,467 & 3,467 & 3,467 & 3,467 & 3,467 \\
\hline
\end{tabular}

Panel B: Household Fixed Effects Regressions

\begin{tabular}{|c|c|c|c|c|c|c|c|c|}
\hline & \multicolumn{4}{|c|}{ Children's Education Decision } & \multicolumn{4}{|c|}{ Children's Clothing Decision } \\
\hline & (1) & $(2)$ & (3) & (4) & (5) & (6) & (7) & (8) \\
\hline & $\begin{array}{c}\text { Head Alone } \\
\text { Makes } \\
\text { Decision }\end{array}$ & $\begin{array}{c}\text { Head } \\
\text { Involved in } \\
\text { Decision }\end{array}$ & $\begin{array}{c}\text { Spouse } \\
\text { Alone } \\
\text { Makes } \\
\text { Decision }\end{array}$ & $\begin{array}{c}\text { Spouse } \\
\text { Involved in } \\
\text { Decision }\end{array}$ & $\begin{array}{c}\text { Head } \\
\text { Alone } \\
\text { Makes } \\
\text { Decision }\end{array}$ & $\begin{array}{c}\text { Head } \\
\text { Involved in } \\
\text { Decision }\end{array}$ & $\begin{array}{c}\text { Spouse } \\
\text { Alone } \\
\text { Makes } \\
\text { Decision }\end{array}$ & $\begin{array}{c}\text { Spouse } \\
\text { Involved in } \\
\text { Decision }\end{array}$ \\
\hline Head: Any Recent US & -0.010 & 0.025 & -0.046 & -0.011 & 0.058 & -0.185 & 0.010 & -0.240 \\
\hline Migration Experience & $(0.014)$ & $(0.101)$ & $(0.097)$ & $(0.021)$ & $(0.058)$ & $(0.180)$ & $(0.159)$ & $(0.127)^{*}$ \\
\hline Hond. Currontly in IS & -0.071 & -0.560 & 0.627 & 0.158 & -0.172 & -0.088 & 0.213 & 0.307 \\
\hline пеан. Cumentiy in us & $(0.088)$ & $(0.186)^{* * *}$ & $(0.180)^{* * *}$ & $(0.096)^{*}$ & $(0.098)^{*}$ & $(0.249)$ & $(0.225)$ & $(0.188)$ \\
\hline Mean of Dep. Variable & 0.034 & 0.807 & 0.132 & 0.909 & 0.028 & 0.424 & 0.320 & 0.771 \\
\hline Observations & 3,467 & 3,467 & 3,467 & 3,467 & 3,467 & 3,467 & 3,467 & 3,467 \\
\hline
\end{tabular}

${ }^{1}$ Reported by spouse, except when missing, in which case responses of head are substituted

Robust standard errors clustered at the household level reported in parentheses below point estimates

Clothing expenditures include value of home production, if any

Other covariates: Number of household members in gender and age-specific groups, dummies for survey year, dummies for survey month, urban dummy

${ }^{*} p<0.1 ; * * p<0.05 ; * * * p<0.01$ 